Article

\title{
Fluid Degradation Measurement Based on a Dual Coil Frequency Response Analysis
}

\author{
Jose M. Guerrero ${ }^{1} \mathbb{1}$, Alejandro E. Castilla ${ }^{1}$, José Ángel Sánchez-Fernández ${ }^{2} \mathbb{D}$ and \\ Carlos A. Platero ${ }^{1, *(D)}$ \\ 1 Department of Automatic Control, Electrical and Electronic Engineering and Industrial Informatics, \\ Universidad Politécnica de Madrid, E-28006 Madrid, Spain; josemanuel.guerrero@upm.es (J.M.G.); \\ alejandro.enfedaque.castilla@alumnos.upm.es (A.E.C.) \\ 2 Department of Hydraulic, Energy and Environmental Engineering, Universidad Politécnica de Madrid, \\ E-28040 Madrid, Spain; joseangel.sanchez@upm.es \\ * Correspondence: carlosantonio.platero@upm.es
}

Received: 17 June 2020; Accepted: 23 July 2020; Published: 26 July 2020

check for Abstract: Electrical industry uses oils for cooling and insulation of several machines, such as
power transformers. In addition, it uses water for cooling some synchronous generators. To avoid
malfunctions in these assets, fluid quality should be preserved. To contribute to this aim, a sensor
that detects changes in fluid composition is presented. The designed sensor is like a single-phase
transformer whose magnetic core is the fluid whose properties will be measured. The response of
this device to a frequency sweep is recorded. Through a comparison between any measurement
and a reference one corresponding to a healthy state, pollutants presence, such as water in oil or
salt in water, can be measured. The performance of the sensor was analyzed through simulation.
In addition, a prototype was built and tested measuring water concentration in oil and salt content
in water. The correlation between pollutant concentration measured with the sensor and known
pollutant concentrations is good.

Keywords: degradation; fault diagnosis; frequency response analysis; predictive maintenance; oil insulation; capacitive sensors; magnetic sensors

\section{Introduction}

Fluid degradation is responsible for numerous equipment failures. Since the use of fluids in industrial processes is extended to practically every area [1], its degradation is one of the most important parameters to control in an industrial installation.

In many installations, fluids are used to evacuate the heat of an industrial process. For this reason, they are exposed to high temperatures that can cause the breakup of their molecules or at least their cracking [2]. This causes an alteration in the characteristics of the fluid [3] and, therefore, a significant reduction in the performance and efficiency of the industrial processes in what they are applied to.

Another problem resulting from fluids degradation is their oxidation [4]. Chemical oxidation reactions take place when a fluid is exposed to air. This oxidation causes an increase in its viscosity [5]. It can even generate sediments [6,7], with the obvious damage the sediments can cause as they are deposited on duct walls or interact with the fluid.

In the electrical field, oils are the fluids most widely used to insulate the conductors in high voltage application machines as well as used as a cooler, e.g., in power transformers [8]. In this case, the degradation of oil is mainly caused by the cellulose decomposition in water, which causes a lack of insulation properties in the oil [9]. 
Due to the fluid degradation issues mentioned above, continuous monitoring is very useful to know the fluid condition at all times. This knowledge allows the timely removal of the different components formed by fluid degradation through techniques such as decantation or distillation or, in situations with an advanced degradation, replacing the fluid with a new one to avoid possible future failures [10].

There are several measurement techniques currently used to evaluate fluid degradation [11,12]. They can be classified as chemical and electrical. These techniques can be complemented by some intelligent techniques to draw a conclusion about the degradation degree of the fluid under consideration. Although some other techniques have been proposed, they have not gained momentum [13].

Among the chemical techniques, dissolved gas analysis (DGA) is the most used [14,15]. It is usually accomplished through chromatography [16]. There are several methods to draw conclusions from a DGA. Most of them are based on ratios of different compound concentrations, such as the Doernenberg or the Rogers' method. The Duval's triangle and pentagons combine several ratios to achieve a diagnostic about transformer oil degradation $[17,18]$. Another technique used to evaluate fluid degradation is ultraviolet spectrophotometry [19]. It is based on determining the absorbance spectra of a fluid sample.

Regarding electrical techniques, they can be classified as time domain and frequency domain [11]. These techniques analyze the dielectric response of the fluids. The polarization and depolarization current (PDC) and the recovery voltage (RV) measurements are time-domain based techniques [20].

The PDC method consists of applying a DC charging voltage to a sample and measuring the polarization current. Then, after removing the DC source, the sample is short-circuited, and the depolarization current is measured [21].

The RV method has a first part similar to the PDC method, i.e., applying a DC voltage to a sample. However, in the RV method, the voltage magnitude applied is measured. Then, the DC source is also removed, and the sample is also short-circuited. After a defined discharging period, the short circuit is cleared, and the remaining voltage is measured [22].

Frequency domain spectroscopy (FDS) consists in measuring the dielectric dissipation factor or loss factor of a sample [23]. From the electrical methods, fluid conductivity can be deduced [24]. It should be taken into account that the values obtained are temperature dependent. Therefore, this parameter should be constant to make comparisons between healthy and degraded fluid samples.

Finally, some methods based on frequency response analysis (FRA) are used to diagnosis the state of electrical machines, such as power transformers [25]. FRA makes a frequency sweep injecting a fixed amplitude voltage, usually $1 \mathrm{~V}$ or $10 \mathrm{~V}$ (root mean square or RMS value), in terminals of the transformer, and analyzes the transfer function between its terminals. Depending on the state of the insulating fluid, i.e., the oil, the transfer function will differ depending on water concentration or temperature. Additionally, impedance polar plots are used [25]. One of the drawbacks of this method is the necessity of stopping the operation to perform the test.

Online technologies for fluid degradation include the measurement of the complex permittivity produced by the insulator fluid among electrodes used as sensors, which changes with an increase in pollutant agents [26].

This research focuses on the design of a new sensor for measuring fluid degradation based on frequency response analysis. This sensor has two coils immersed in the fluid under test. Attending to the gain variation within a defined frequency range, the concentration of pollutant agents can be determined.

The paper is structured as follows: Section 2 explains the design of the proposed sensor. Then, Section 3 describes a simulation model of the sensor, and Section 4 reports the experimental measurements made to validate the designed sensor. Finally, Section 5 presents the main contribution of the paper. 


\section{Materials and Methods}

The proposed sensor is like a transformer where its windings are two coils, and its magnetic core is the fluid under test, as shown in Figure 1. The voltage applied to the first coil causes the magnetic flux common to both coils. This magnetic flux induces a voltage in the second coil. This induced voltage is measured by the FRA test equipment.

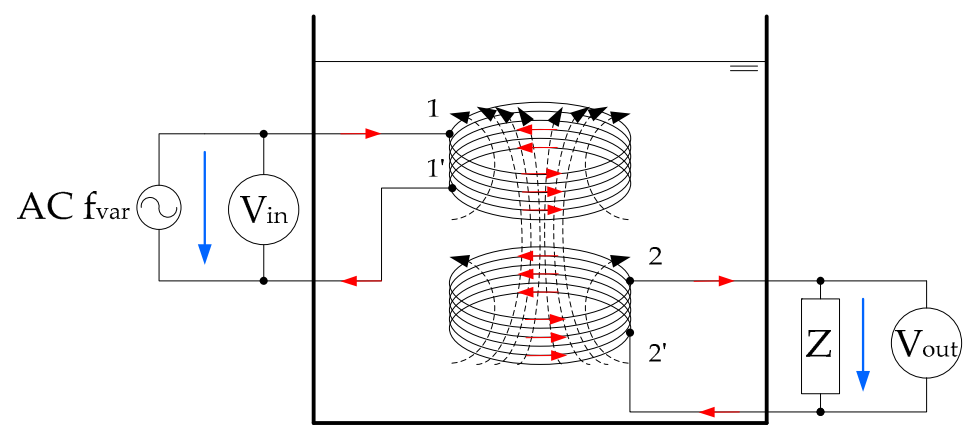

Figure 1. Fluid core dual-coil sensor, magnetic flux scheme.

Both windings are also capacitively coupled. This capacitive coupling is increasingly important as the frequency of the applied voltage increases. The simplified equivalent circuit is displayed in Figure 2. The increase or decrease in fluid permittivity implies higher or lower leakage currents in the system, as can be seen in the scheme proposed in Figure 2.

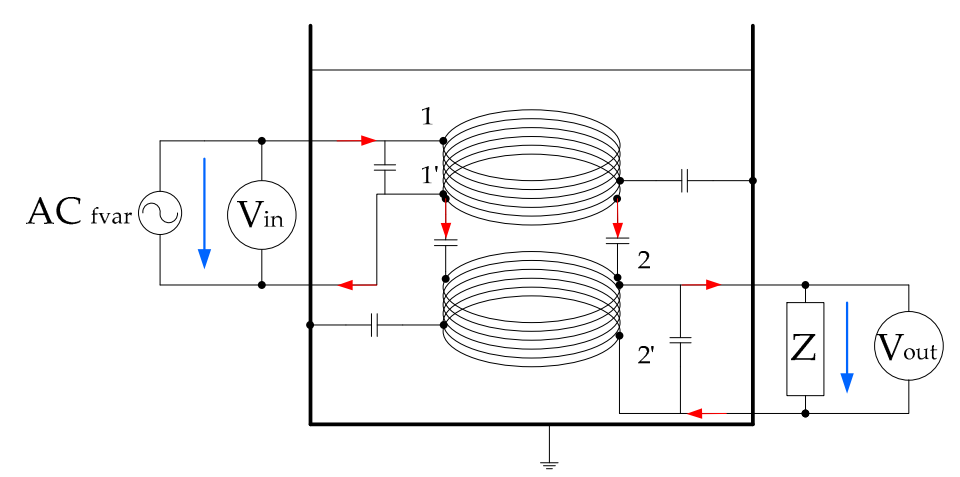

Figure 2. Frequency response analysis (FRA) test fluid core dual-coil sensor capacity couplings simplified circuit.

And finally, the effect of fluid resistivity $(\rho)$ modifies the energy losses in these couplings. The insulation resistance to ground, between the windings and between turns is modified in case of fluid degradation. The simplified circuit of the fluid core dual coil is shown in Figure 3.

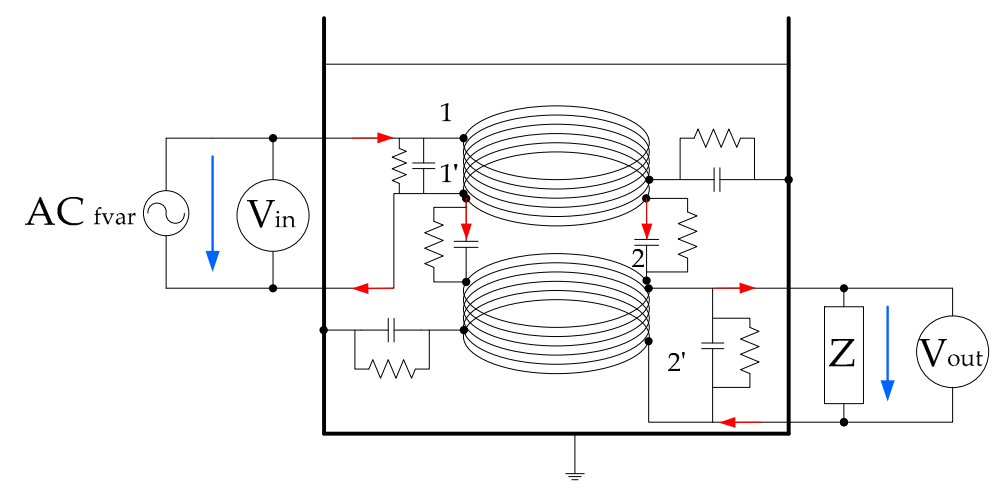

Figure 3. FRA test fluid core dual-coil sensor simplified circuit. 
This phenomenon is quite difficult to characterize due to the different compounds present in a fluid [27]. The interactions among these compounds can cause resistance changes. The variations in conductivity can be linear functions, such as in $\mathrm{H}_{2} \mathrm{SO}_{4}-\mathrm{H}_{2} \mathrm{O}$ electrolytes, logarithmic functions, as in $\mathrm{NaCl}-\mathrm{H}_{2} \mathrm{O}$ electrolytes, etc., which makes its characterization difficult. The design of the fluid core dual-coil sensor prototype is shown in Figure 4a. A coil was placed on each holder. These coils had $\mathrm{N}=200$ turns each, with a circular conductor section of $S=0.2 \mathrm{~mm}^{2}$ and $0.504 \mathrm{~mm}$ diameter. The two holders must be placed vertically and an empty cavity between them. This cavity was filled with fluid when the sensor was submerged in it. The number of turns was 200 to keep the sensor compact but with high enough resolution to observe fluid behavior.

This geometry allowed the fluid to circulate between both coils. A 3D representation of the two coil holders, one for each wiring confronted in a vertical disposition, is pictured in Figure $4 \mathrm{~b}$. This disposition allowed the free fluid circulation into the core column.

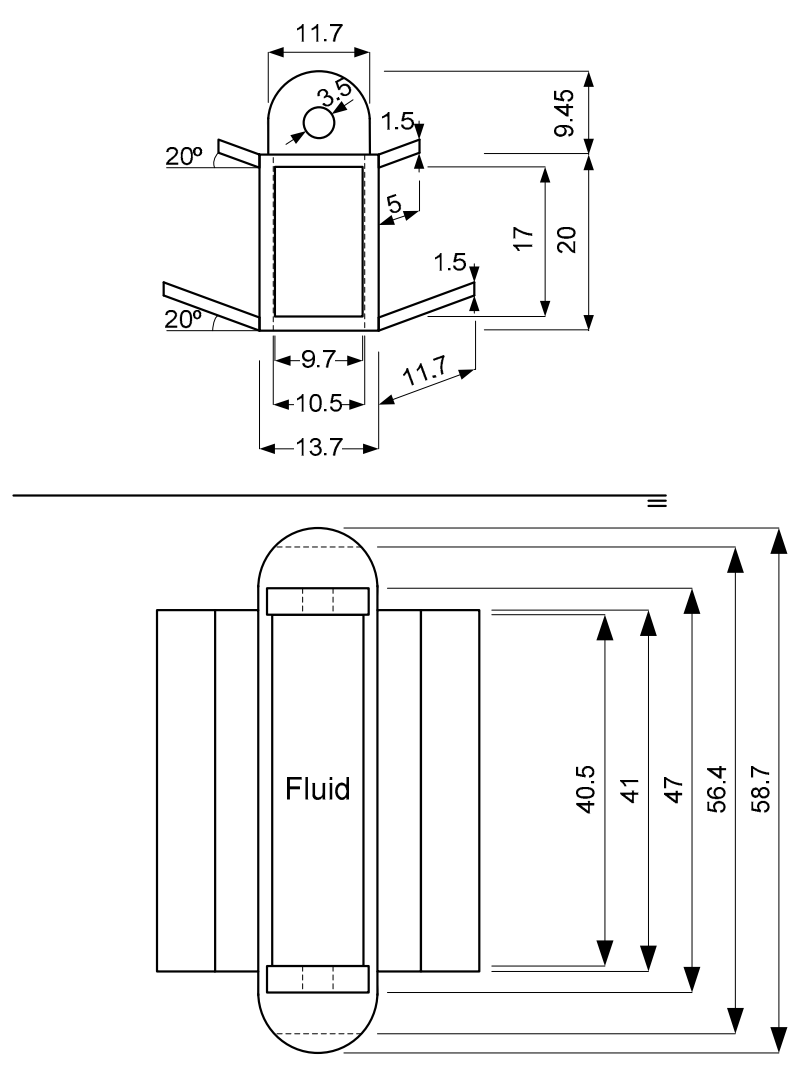

(a)

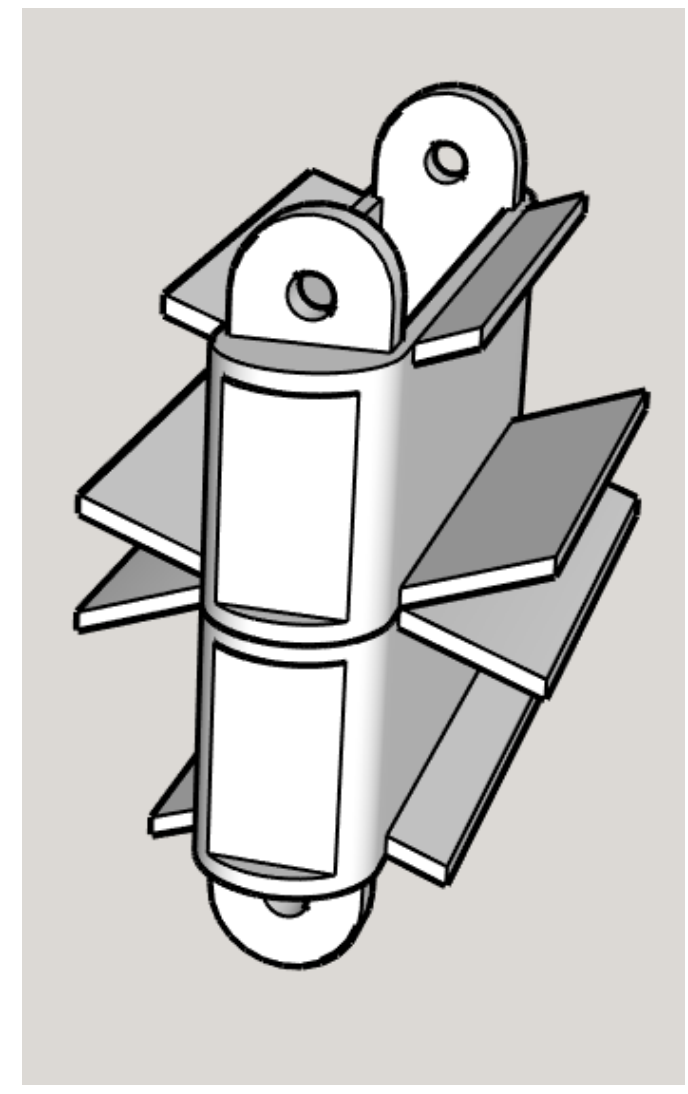

(b)

Figure 4. Dual coil holders' design (a) Fluid core dual coil holder dimensions. (b) Dual coil holders' disposition. They were aligned vertically for the free fluid circulation between them.

Once the double coil was submerged in the fluid recipient and this fluid surrounded the sensor, a frequency response analyzer (FRA) test equipment was connected between the terminals of each coil, as shown in Figure 5. The input voltage $\left(\mathrm{U}_{\mathrm{in}}\right)$ was applied between 1 and $1^{\prime}$ terminals of one coil. The amplitude was $1 \mathrm{~V}$, and the frequency went from $20 \mathrm{~Hz}$ to $20 \mathrm{MHz}$. The voltage in the other coil $\left(\mathrm{U}_{\text {out }}\right)$ was measured by the FRA test equipment. The input impedance of the FRA test equipment was normally a $50 \Omega$ resistor. 
The FRA test consisted of contrasting the input with the output voltage in the different frequencies range as (1):

$$
A(d B)=20 \cdot \log \left(\frac{\mathrm{U}_{\text {out }}}{\mathrm{U}_{\text {in }}}\right)
$$

If the composition of the fluid changes, then the FRA test results will also change.

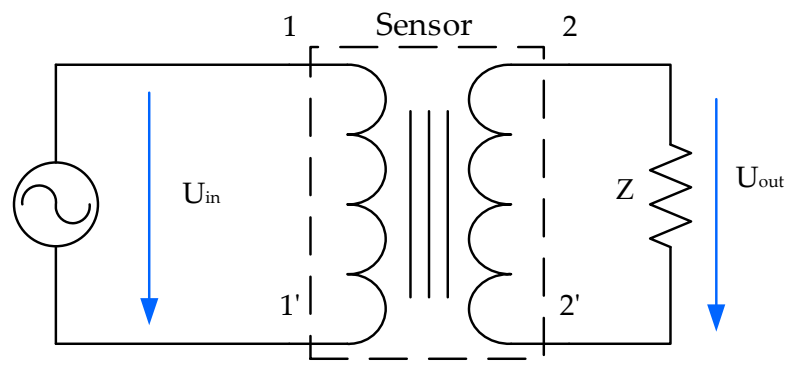

Figure 5. Frequency response analysis test equipment connections in the fluid core double coil sensor.

To sum up, the Frequency Response Analysis test results, in general, depend on several factors related to the fluid as magnetic permeability $(\mu)$, permittivity $(\varepsilon)$, and resistivity $(\rho)$. In the case of fluid degradation, a change in its composition occurs, and, therefore, the FRA test results would change. However, it should be noted that, in the cases presented (water in oil and salt in water), there are only changes in resistivity.

The inductive coupling will be significant in the low-frequency range. However, the capacitive coupling of the windings will have more importance at the high-frequency range. As the capacitance increases, the impedance between conductors and ground decreases, while the voltage drop in the system is lower, and the gain response gets higher.

Finally, if water is added to an insulating fluid, the resistivity should decrease, making this fluid a better conductor for leakage currents. This implies a decrease in fluid resistance and, by consequence, a lower voltage drop in the transfer function. For this reason, the gain obtained by registering $\mathrm{U}_{\text {out }}$ will be higher.

\section{Simulations}

To make simulations, a model of the proposed sensor was needed. This model is shown in Figure 6. The calculation process consisted of solving this circuit for different frequencies between $20 \mathrm{~Hz}$ and $20 \mathrm{MHz}$. The individual calculation took into account the circuit parameters, the variable frequency voltage source, and the voltmeter impedance. Therefore, the $U_{\text {out }}$ was obtained, and circuit gain could be calculated, as expressed in Equation (1).

The model was based on the traditional equivalent circuit of a transformer, but included the capacitive couplings and insulation resistances. Models similar to the one presented here can be found in the literature [28-30].

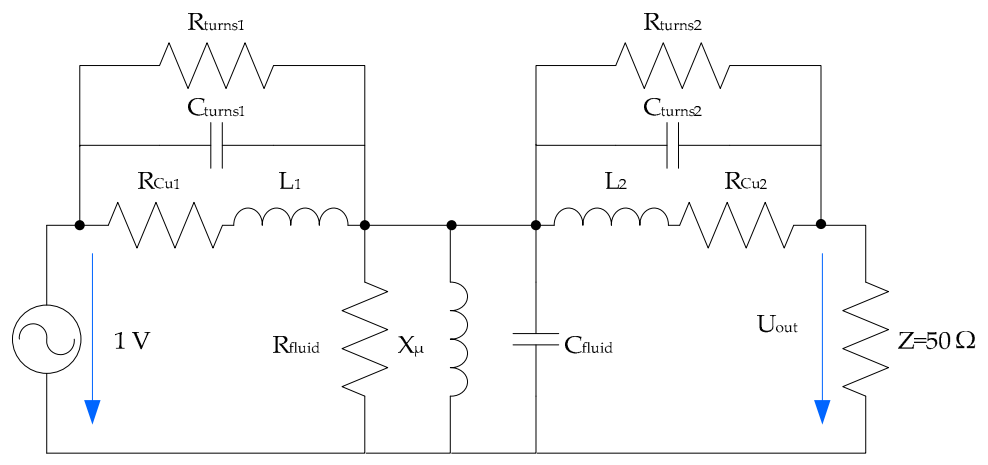

Figure 6. Electrical equivalent circuit used for simulations. 
The parameters of the equivalent circuit were calculated, attending to the geometrical coil disposition and materials, using well-known formulae. Later, they were fine-tuned, attending to the initial conditions of an FRA test in the unpolluted main fluid.

The parameters of the equivalent circuit were:

The coils resistances $R_{\mathrm{Cu} 1}$ and $\mathrm{R}_{\mathrm{Cu} 2}$ were calculated from copper resistivity, wire section, length, and number of turns, as can be seen in Equation (2):

$$
\mathrm{R}_{\mathrm{Cu}}=\rho_{\mathrm{Cu}} \cdot \frac{\mathrm{N} \cdot \mathrm{l}_{\mathrm{Cu}}}{\mathrm{S}_{\mathrm{Cu}}}
$$

where $\mathrm{l}_{\mathrm{Cu}}$ was, according to Figure $4,0.167 \mathrm{~m}$, the wire section $\left(\mathrm{S}_{\mathrm{Cu}}\right)$ was $0.2 \mathrm{~mm}^{2}$, and the resistivity at $25^{\circ} \mathrm{C}$ was $0.0171 \Omega \cdot \mathrm{mm}^{2} / \mathrm{m}$.

The initial values for the induction $\mathrm{L}_{1}$ and $\mathrm{L}_{2}$ were calculated as in (3):

$$
\mathrm{L}_{1}=\mathrm{L}_{2}=\frac{N^{2}}{\frac{1}{\mu} \cdot \frac{l}{S}}
$$

where $l$ was the average length of the magnetic circuit: $0.0867 \mathrm{~m}$ (2 times the length of the sensor limbs and the top and bottom yokes), and $S$ was the section of the empty window of the sensor where the fluid circulates $\left(3.93 \times 10^{-4} \mathrm{~m}^{2}\right)$.

Additionally, the capacitance between the sensor to the ground was estimated as the interaction between two equivalent wires of diameter, $d, 0.504 \mathrm{~mm}$ in the middle of each coil, and using a relative electrical permittivity of 80.5 , which corresponded to distillated water. Then (4) can be expressed as:

$$
\mathrm{C}_{\text {fluid }}=\frac{\varepsilon_{r} \varepsilon_{o}}{\ln \frac{\mathrm{D}_{\mathrm{Cu} 1 \mathrm{Cu} 2}}{d}}
$$

where $\mathrm{D}_{\mathrm{Cu} 1 \mathrm{Cu} 2}$ was the distance between equivalent wires.

The capacitance between turns has been calculated as the capacitance between two adjacent wires $2 \mu \mathrm{m}$ apart and using the known expression below, (5):

$$
C_{\text {turns }}=\frac{\varepsilon_{r} \varepsilon_{o}}{\ln \frac{2 d+2[\mu \mathrm{m}]}{d}}
$$

On the other hand, the resistances between turns $\left(R_{\text {turns1 }}, R_{\text {turns2 }}\right)$ and between coils were considered through the fluid $\left(\mathrm{R}_{\text {fluid }}\right)$. So, they were calculated as a direct multiplication between the fluid electrical resistivity (distillated water $=3 \mathrm{M} \Omega / \mathrm{cm}$ ) and the insulation length between cables or between equivalent cables. The magnetizing induction was initially considered 5 times lower than $\mathrm{L}_{1}$ and $\mathrm{L}_{2}$ to provoke high magnetizing currents.

Finally, the parameters were adjusted, taking as reference the response to a test of the sensor submerged in a healthy fluid. The adjusted parameters are shown in Table 1.

Table 1. Simulation model, initial parameters.

\begin{tabular}{ccc}
\hline Parameter & Value & Units \\
\hline $\mathrm{R}_{\mathrm{Cu} 1}$ & 2.86 & $\Omega$ \\
$\mathrm{L}_{1}$ & $9.87 \times 10^{-4}$ & $\mathrm{H}$ \\
$\mathrm{R}_{\mathrm{Cu} 2}$ & 2.86 & $\Omega$ \\
$\mathrm{L}_{2}$ & $9.87 \times 10^{-4}$ & $\mathrm{H}$ \\
$\mathrm{R}_{\text {turns1 }}$ & 2000 & $\Omega$ \\
$\mathrm{C}_{\text {turns1 }}$ & $9.05 \times 10^{-10}$ & $\mathrm{~F}$ \\
$\mathrm{R}_{\text {turns2 }}$ & 2000 & $\Omega$ \\
$\mathrm{C}_{\text {turns2 }}$ & $9.05 \times 10^{-10}$ & $\mathrm{~F}$ \\
$\mathrm{R}_{\text {fluid }}$ & $2 \times 10^{7}$ & $\Omega$ \\
$\mathrm{L}_{\mu}$ & $1.97 \times 10^{-4}$ & $\mathrm{H}$ \\
$\mathrm{C}_{\text {fluid }}$ & $1.63 \times 10^{-10}$ & $\mathrm{~F}$ \\
\hline
\end{tabular}


To verify the proposed methodology, circa 200 simulations were performed based on the already described equivalent circuit varying $R_{\text {turns1 }}, R_{\text {turns2 }}, C_{\text {turns1 }}, C_{\text {turns } 2}, L_{\mu}, R_{\text {fluid }}$ and $C_{\text {fluid }}$ to achieve the healthy-state fluid transfer function. The fitting process was done by comparing the simulation with an experimental healthy-state salt in the water test, taking as reference the gain value in the plateau (between $200 \mathrm{~Hz}$ and $10 \mathrm{kHz}$ ) and the first resonance gain (between 200 and $500 \mathrm{kHz}$ ), in dB. As shown in Table 1, the impedances of the equivalent circuit of the proposed sensor were different from the usual ones of iron core transformers.

The simulations were performed, varying different parameters of the equivalent circuit. They took into account variations of the core-magnetizing inductance, fluid resistance, and capacitance with the addition of component B into a fluid A. The simulations corresponded to the case of water polluted with salt. Therefore, different salt (component B) quantities were added to water (main fluid). Increasing the frequency from $20 \mathrm{~Hz}$ to $20 \mathrm{MHz}$, emulating the sweeping stages of FRA equipment, the following results were achieved varying the fluid resistance, inductance, and capacitance for salt additions of $0,10,20,30 \ldots$, up to $100 \mathrm{ppm}$ weight of salt in $1 \mathrm{~L}$ of water and registering $\mathrm{U}_{\text {out }}$ (see Figure 7). Furthermore, the values of the parameters that depend one fluid composition are displayed in Table 2 for concentrations of $10,20,50$, and 100 ppm of salt in water.

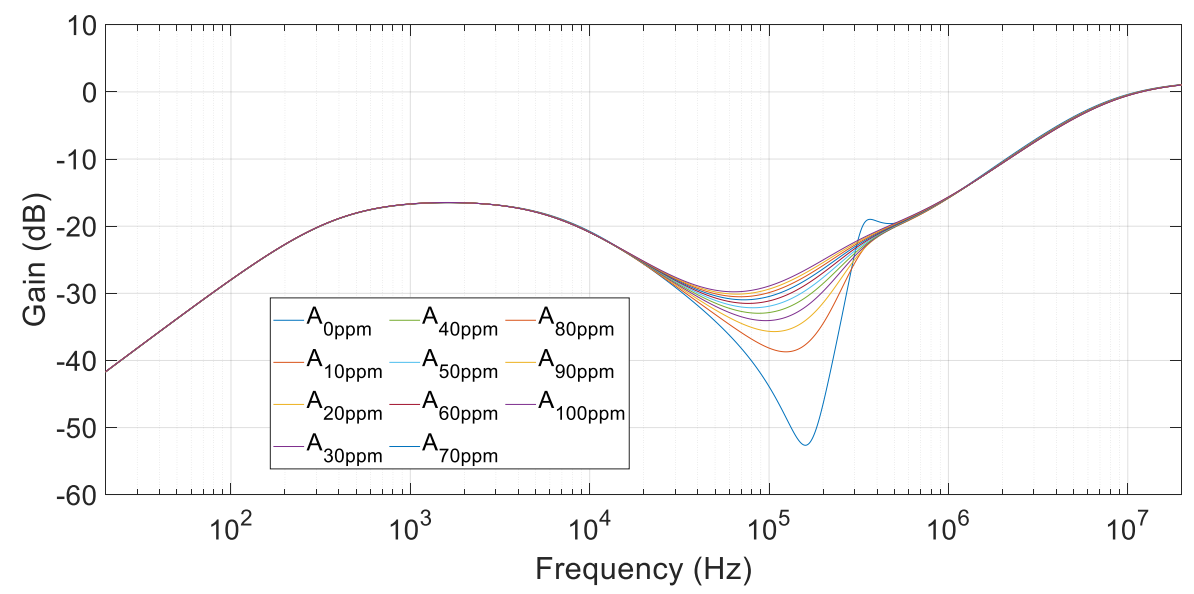

Figure 7. Simulation results for different salt in water concentrations, from $0 \mathrm{ppm}$ up to $100 \mathrm{ppm}$.

In these simulations, where salt was added to water, the resistance parameter was highly affected by the addition of the pollutant agent. This was caused by the ions that appeared when salt dissolved in distilled water. Then, the variation of $R_{\text {turns1 }}$ and $R_{\text {turns2 } 2}$ were the main factors of the resonant frequency displacement. A lower value of these parameters implies a softer and lower-frequency resonance.

Table 2. Simulation model, parameters' evolution when the salt concentration in water varies.

\begin{tabular}{ccccc}
\hline Parameter & $\mathbf{1 0} \mathbf{~ p p m}$ & $\mathbf{2 0} \mathbf{~ p p m}$ & $\mathbf{5 0 ~} \mathbf{~ p m}$ & $\mathbf{1 0 0} \mathbf{~ p p m}$ \\
\hline $\mathrm{L}_{1}(\mathrm{H})$ & $9.87 \times 10^{-4}$ & $9.87 \times 10^{-4}$ & $9.87 \times 10^{-4}$ & $9.87 \times 10^{-4}$ \\
$\mathrm{~L}_{2}(\mathrm{H})$ & $9.87 \times 10^{-4}$ & $9.87 \times 10^{-4}$ & $9.87 \times 10^{-4}$ & $9.87 \times 10^{-4}$ \\
$\mathrm{R}_{\text {turns1 }}(\Omega)$ & 780 & 612 & 446 & 349 \\
$\mathrm{C}_{\text {turns1 }}(\mathrm{F})$ & $9.05 \times 10^{-10}$ & $9.05 \times 10^{-10}$ & $9.05 \times 10^{-10}$ & $9.05 \times 10^{-10}$ \\
$\mathrm{R}_{\text {turns2 }}(\Omega)$ & 780 & 612 & 446 & 349 \\
$\mathrm{C}_{\text {turns2 }}(\mathrm{F})$ & $9.05 \times 10^{-10}$ & $9.05 \times 10^{-10}$ & $9.05 \times 10^{-10}$ & $9.05 \times 10^{-10}$ \\
$\mathrm{R}_{\text {fluid }}(\Omega)$ & $7.80 \times 10^{6}$ & $6.12 \times 10^{6}$ & $4.46 \times 10^{6}$ & $3.49 \times 10^{6}$ \\
$\mathrm{~L}_{\mu}(\mathrm{H})$ & $1.97 \times 10^{-4}$ & $1.97 \times 10^{-4}$ & $1.97 \times 10^{-4}$ & $1.97 \times 10^{-4}$ \\
$\mathrm{C}_{\text {fluid }}(\Omega)$ & $1.63 \times 10^{-10}$ & $1.63 \times 10^{-10}$ & $1.63 \times 10^{-10}$ & $1.637 \times 10^{-10}$ \\
\hline
\end{tabular}

The brine achieved implies an exponential reduction in water resistance or fast growth of the conductivity that increased from $0.5 \mu \mathrm{S} / \mathrm{cm}$ to approximately $5000 \mu \mathrm{S} / \mathrm{cm}$ for a $0.05 \mathrm{~mol} / \mathrm{L}$ at a standard 
temperature of $25^{\circ} \mathrm{C}$ dissolution according to [27]. The capacitance and inductance had small changes. The capacitance became lower than in healthy conditions because the relative permittivity of a $2 \mathrm{~mol} / \mathrm{L}$ brine was 55 versus 80.5 of distilled water. However, the differences were extremely low due to the small variations in salt concentrations. The inductive part of the system also remained nearly constant, being salt a diamagnetic material.

Although different concentrations of pollutant produced different results in the FRA tests that lead to different $\mathrm{R}, \mathrm{L}, \mathrm{C}$ values, the minimum peak achieved in every frequency sweep was located in the same frequency range $(20 \mathrm{kHz}-200 \mathrm{kHz})$, as shown in Figure 7 . This difference between relative minimums allowed the sensor to distinguish the extent to which the polluting agent was affecting the main fluid. To this aim, the FRA results from a polluting agent concentration should be compared to the corresponding healthy state FRA test ( 0 ppm of salt in water).

As the interaction between fluids alters the frequency response, a database should be created with different fluid contaminations depending on the application of fluid monitored. The simulations were performed for salt in water. Other fluids were not simulated.

Once the simulations were carried out, some experimental tests in a prototype must be done to validate the proposed sensor. In addition, the parameters that change with contaminations should be determined.

\section{Experimental Setup}

According to the proposed methodology, impurities or degradation symptoms in fluids could be detected by performing an FRA test with the proposed sensor. However, the fluid must be tested previously in reference conditions. This first test is considered a reference test. Future tests should be compared to the reference test to determine if there is any change in fluid composition.

In the first set of tests, some quantities of $\mathrm{NaCl}$ were added to water to modify its properties. In the second set of tests, some quantities of water were added to transformer oil, emulating the degradation in a real power transformer.

Before the experiments, an experimental setup was prepared. It consisted of the proposed sensor that was going to be submerged in the tested fluid (See Figure 8). In the first coil, a voltage source applied a $1 \mathrm{~V}_{\mathrm{RMS}}$ sinusoidal wave. The frequency of the voltage source varied from $20 \mathrm{~Hz}$ to $20 \mathrm{MHz}$. The voltage in the second coil was measured and compared to the voltage applied to the first one. The FRA test equipment's main characteristics are displayed in Table 3.

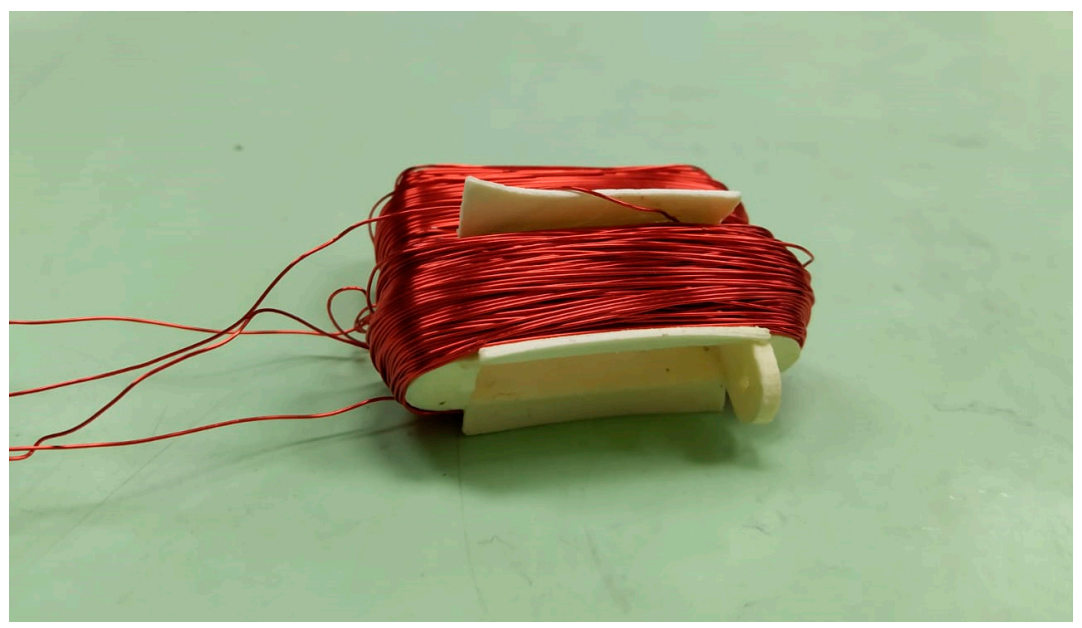

Figure 8. Fluid core double coil sensor used in the experimental setup.

Once the connections were done, the sensor was submerged in a two-liter container, as shown in Figure 9. The container was filled with the fluid under test, while a second dissolution was prepared outside with the pollutant agent. 
Table 3. Frequency response analysis (FRA) equipment's main characteristics.

\begin{tabular}{cc}
\hline Parameter & Value \\
\hline Frequency range & $10 \mathrm{~Hz}-20 \mathrm{MHz}$ \\
Output Impedance & $50 \Omega$ \\
Accuracy (down to $-80 \mathrm{~dB}$ ) & $<0.1 \mathrm{~dB}$ \\
Accuracy (down to $-100 \mathrm{~dB}$ ) & $<0.3 \mathrm{~dB}$ \\
\hline
\end{tabular}

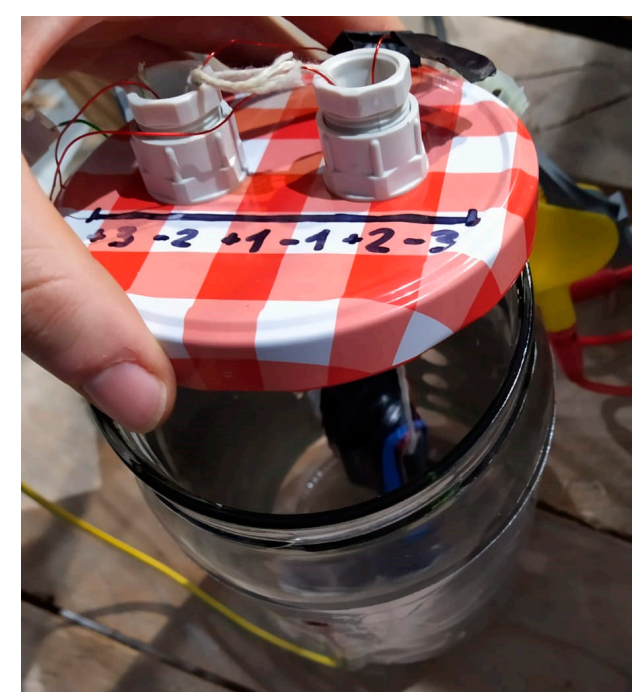

Figure 9. Two-liter container with the fluid core double coil sensor.

The tests were performed at constant temperature conditions. The container was placed in a controlled temperature tank (see Figure 10). The temperature of the reference test should be close to the normal condition operating temperature, e.g., oil and water tests, emulating a transformer cellulose decomposition from the insulation materials, were performed at $70{ }^{\circ} \mathrm{C}$. Then, the addition of a second component was done with the aim of carrying out different FRA tests with different pollutant agent concentrations. The FRA connections to the experiment are displayed in Figure 11, where the whole system can be observed (from left to right: FRA Equipment, computer for signal monitoring, and the recipient with the tested fluid). Once the connections were done, the FRA tests were performed, taking around 5 min per test.

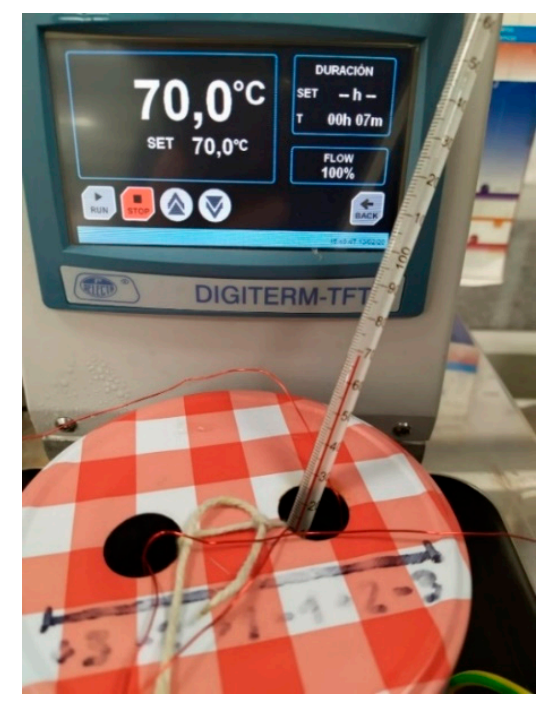

Figure 10. Controlled temperature of the dissolution of oil and water at $70^{\circ} \mathrm{C}$. 


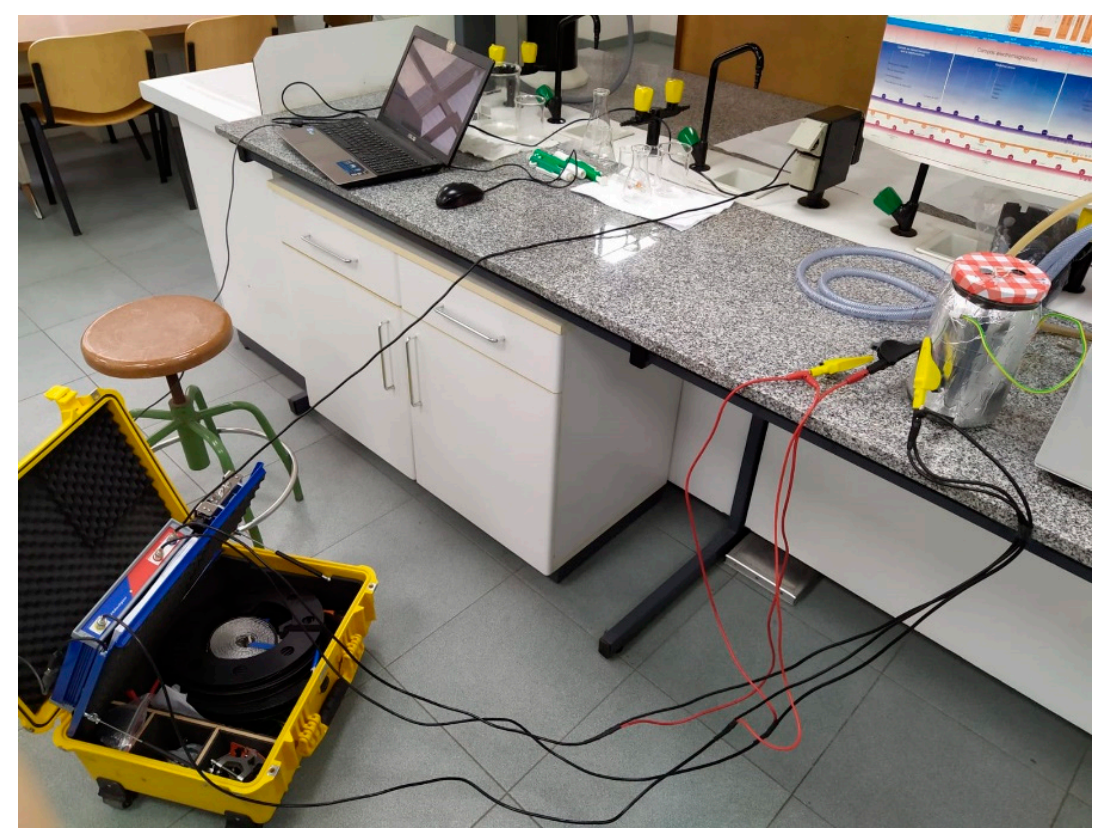

Figure 11. FRA test connections to the two-liter container. No thermostable bath was done in this test.

As electric conductivity depends on temperature [31], the FRA test results will be affected by operating temperature. Therefore, the temperature of the different tests should be constant. Hence, contrasting the tests and the reference test can be done. In this paper, only one-constant temperature tests were carried out.

\subsection{Distilled Water Contaminated with Salt Experimental Tests}

Firstly, a set of experiments with pure distilled water with additions of salt was conducted. The tests were performed with $1.7 \mathrm{~L}$ of water in a recipient. An additional dissolution of salt in $1 \mathrm{~L}$ of water was used to add small ppms of salt to the first recipient. With those recipients, the addition of the brine in the first container was progressive, then only $2.7 \mathrm{~L}$ of water and less than $1 \mathrm{~g} \mathrm{of} \mathrm{NaCl}$ were used.

They consisted of filling the container with pure distilled water and dive the sensor in the container. After this, an FRA test was performed, obtaining the results shown in Figure 12. In this figure, the frequency response of pure distilled water can be seen. This test corresponded to a healthy state of the fluid, and it has been be considered as the reference test. The frequency of test injection equipment went from $20 \mathrm{~Hz}$ up to $20 \mathrm{MHz}$.

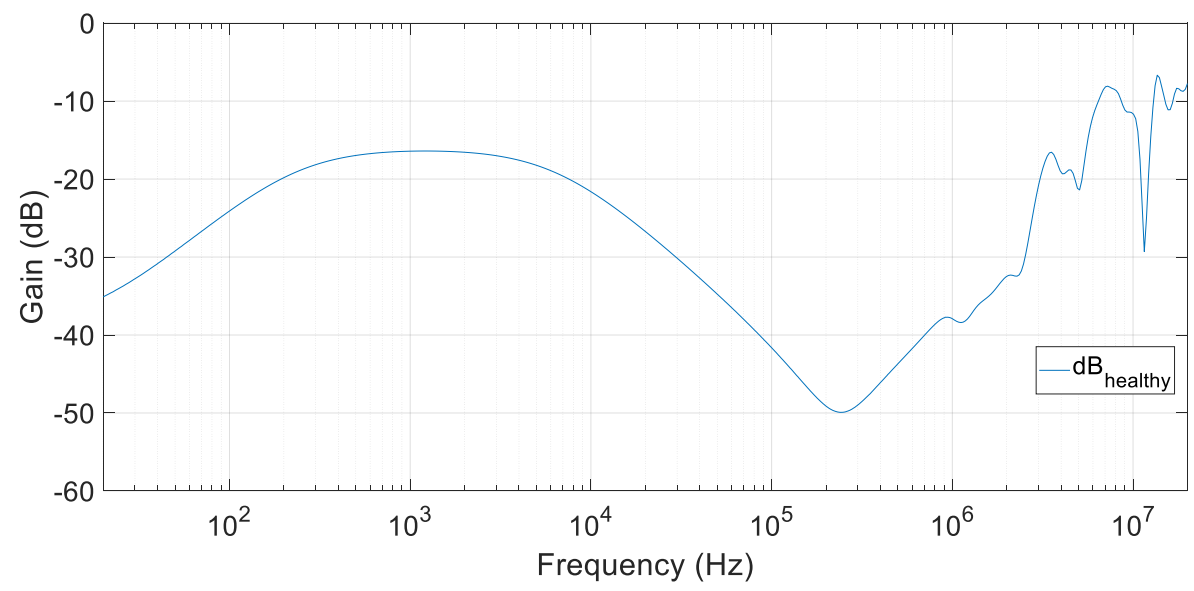

Figure 12. FRA test results with pure distillated water. Reference test. 
The next step was the addition of salt at an approximate ratio of $15 \mathrm{ppm}$. The effects in the frequency response can be observed in Figures 13 and 14. In them, the results of tests for salt concentrations varying from $15 \mathrm{ppm}$ to $305 \mathrm{ppm}$ are shown. The FRA results were clearly different depending on the quantity of salt in water. As can be observed, the resonant frequency and amplitude changed in a monotonic way. This is an important fact to determine the quantity of salt in the water. In these experimental tests, a resolution of $15 \mathrm{ppm}$ was corroborated.

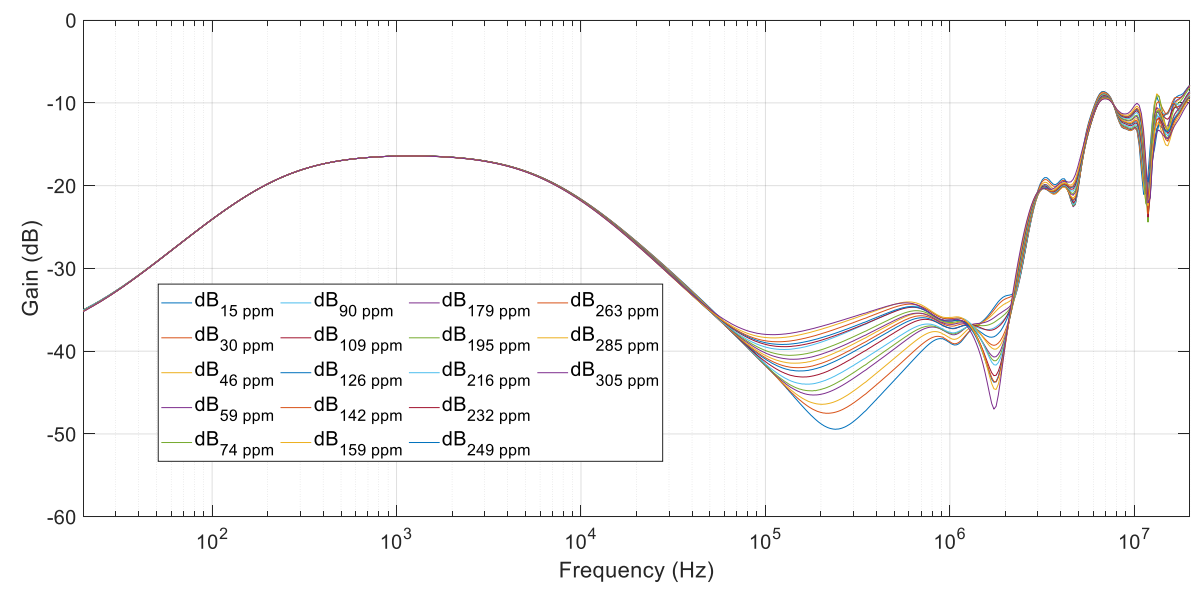

Figure 13. FRA test results from $15 \mathrm{ppm}$ up to $305 \mathrm{ppm}$ of salt in water.

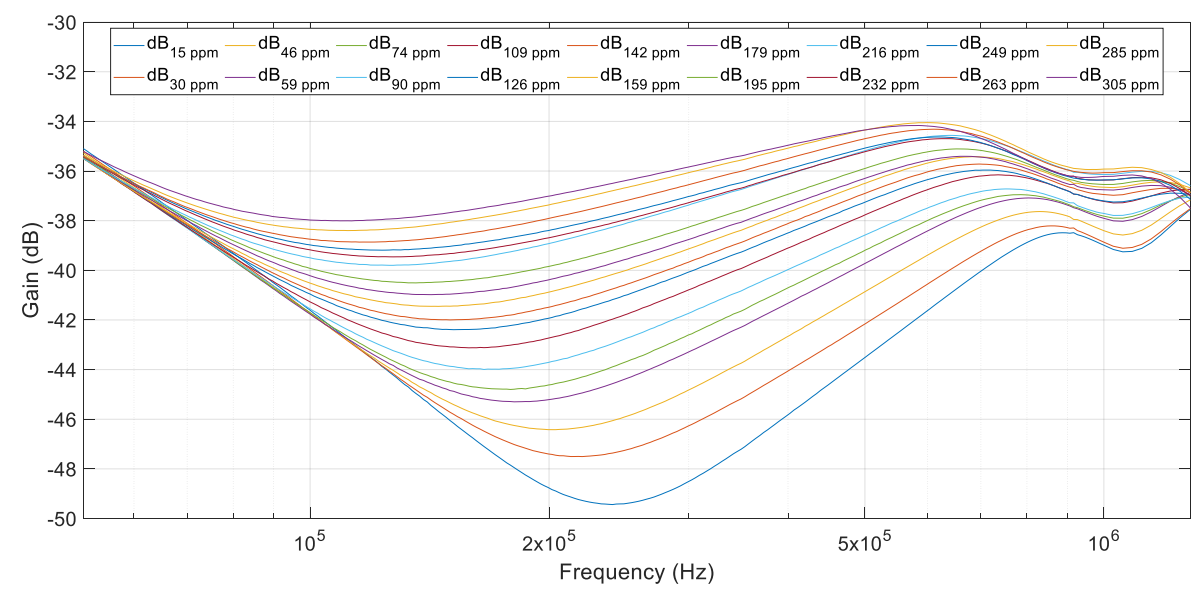

Figure 14. FRA test results from 15 ppm up to 305 ppm of salt in water. Zoom (100 kHz to $500 \mathrm{kHz})$.

A comparison of the last test, with water polluted at $305 \mathrm{ppm}$ of salt, and the reference test, with pure distilled water, is presented in Figure 15. It can be clearly observed how the frequency response varied in the range of $100-500 \mathrm{kHz}$ (see Figure 14). However, at low frequencies, impedance remained almost constant, and the FRA results were not influenced by the addition of salt.

In Figure 15, a second resonance appeared that should be provoked by the added salt. When comparing this figure with Figure 13, this second resonant peak did not appear in simulations. This is because this model has been fitted to get an optimum response in the frequency range of up to $500 \mathrm{kHz}$.

To estimate the salt quantity by the analysis of the FRA results, the gains at the resonant frequency were used. These gains corresponded to the minimum gains in the frequency range from $100 \mathrm{kHz}$ to $500 \mathrm{kHz}$. The minimum gains vary in a monotonic way, as shown in Figure 16. 


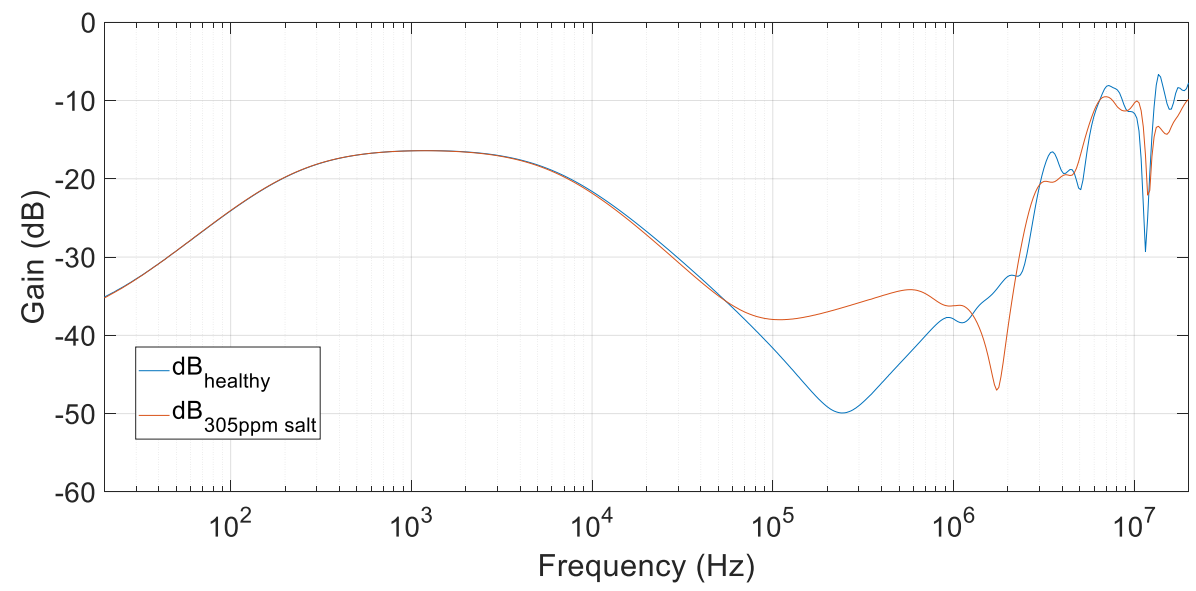

Figure 15. FRA tests for a transformer with distillated water core with salt. Tests compare distilled water and water with 305 ppm of salt.

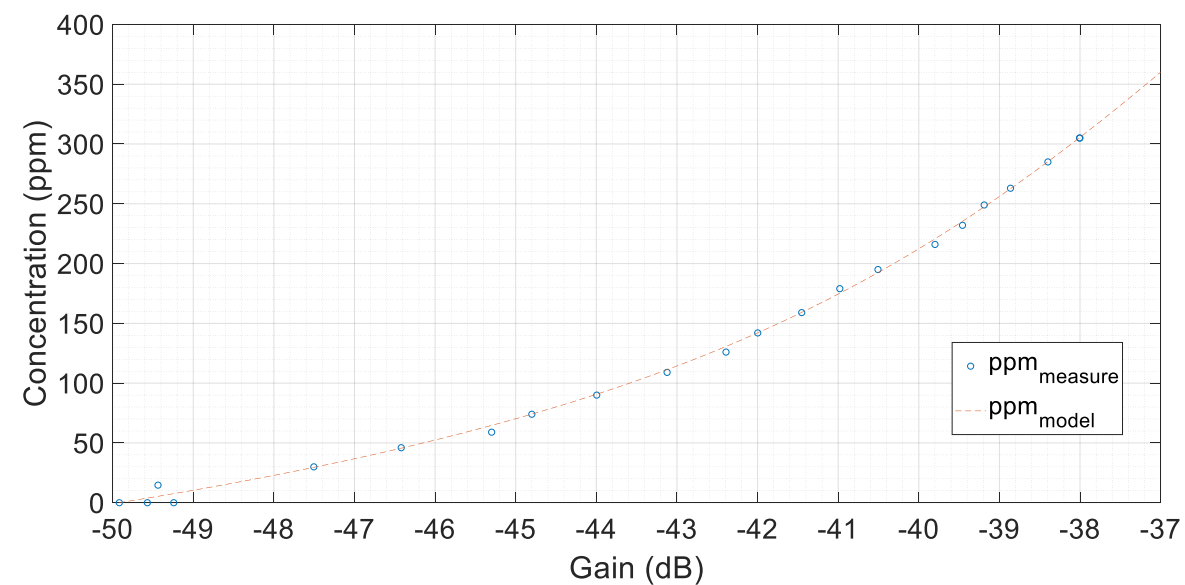

Figure 16. Measures of the minimum value of gains in the range of $100 \mathrm{kHz}$ up to $500 \mathrm{kHz}$ and the fitted curve.

Data presented in Figure 16 can be fitted by Equation (6) achieving a coefficient of determination, $\mathrm{R}^{2}$, of 0.9987:

$$
C[\mathrm{ppm}]=f(A[\mathrm{~dB}])=k_{1} \cdot e^{\alpha \cdot A}+k_{2} \cdot e^{\beta \cdot A}
$$

where

$$
k_{1}=1.102 \times 10^{5} ; k_{2}=-24.13 ; \alpha=0.1512 ; \beta=-0.01762
$$

These results corroborate the possibility of characterizing water contamination with salt by FRA analysis.

\subsection{Oil Contaminated with Water Experimental Tests}

These second laboratory experimental tests aimed to detect water in power transformer oil. During the lifetime of power transformers, insulation degrades, especially at the end of their useful life.

During this process, water is released from cellulose, which is one of the main components of the insulation system of a power transformer. In addition, water is mixed with oil; therefore, it is essential to monitor the content of water in oil. High concentrations of water can initiate partial discharges and even cause catastrophic failures in power transformers. These phenomena occur when the cellulose of the insulating Kraft paper decomposes.

In this case, the tests were performed with $1.7 \mathrm{~L}$ of oil and an additional dissolution of 1 gram of water in $1 \mathrm{~L}$ of oil that allowed the addition of water in 1 or $10 \mathrm{ppm}$ increments to the main recipient. 
The objective of these experimental tests was to measure in ppm the concentration of water in oil using FRA tests.

Numerous tests with oil and water were performed. The test results are displayed in Figure 17. The procedure was similar to the previous tests. However, now the pollutant agent was water. The tests were carried out from 1 ppm up to 1000 ppm of water in $1.7 \mathrm{~L}$ of oil. The water contamination addition steps were $1,2 \ldots$ up to $10 \mathrm{ppm}, 10,20 \ldots$ up to 100 and finally $100,200 \ldots$ up to $1000 \mathrm{ppm}$.

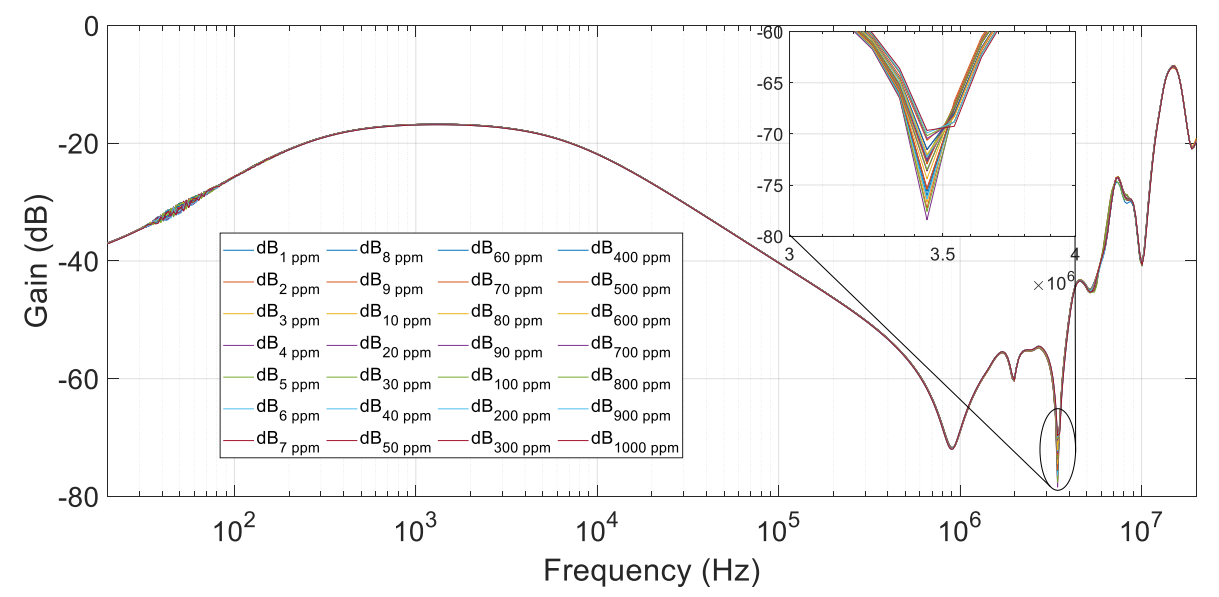

Figure 17. FRA test results for dissolutions of oil and water from 1 to $1000 \mathrm{ppm}$ of water in oil.

In these tests, the resonant frequency range went from $3 \mathrm{MHz}$ up to $4 \mathrm{MHz}$ because of the higher insulation capacity and resistance of oil compared with water. In this range, the variation in gain was small but not negligible. Comparing Figure 17 with Figure 15, in oil and water mixtures, the frequency resonance was already present in a healthy state, and water addition smoothed it. However, in salt and water mixtures, the behavior was the opposite.

The evidence of how the FRA varied due to the addition of water is shown in Figure 18, where the gain was plotted against the concentration of water in oil. In these experiments, 1 ppm resolution was achieved. To get this sensitivity, a good fluid circulation and homogenization of the mixture was required.

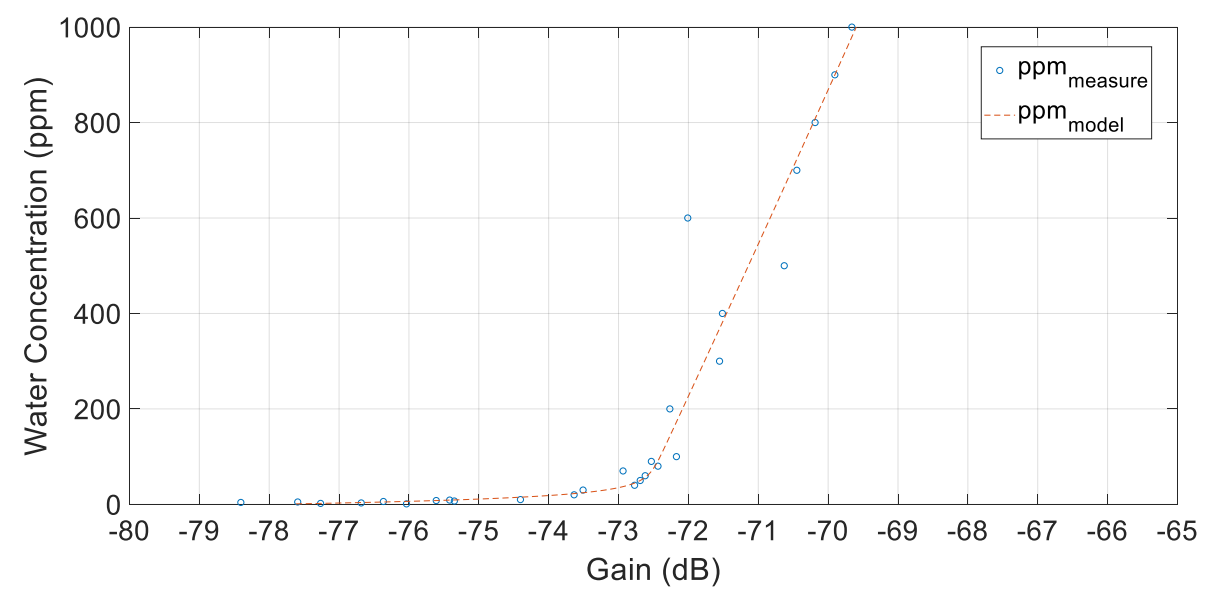

Figure 18. Measures of the minimum value of gain in the range of $3 \mathrm{MHz}$ up to $4 \mathrm{MHz}$ and the fitted curve.

In this case, the most accurate model adjustment was a model of gain from water concentration, as shown in (7)

$$
A[\mathrm{~dB}]=f(C[\mathrm{ppm}])=k_{1}^{\prime} \cdot e^{\gamma \cdot C}+k_{2}^{\prime} \cdot e^{\delta \cdot C}
$$


Afterward, the concentration could be estimated thanks to a lookup table made from the previous model. In this case, the model parameters were:

$$
k_{1}^{\prime}=-5.279 ; k_{2}^{\prime}=-72.72 ; \gamma=0.07425 ; \delta=-4.391 \times 10^{-5}
$$

with a regression coefficient of 0.9843 .

Due to the low conductivity of the transformer oil, the accuracy of the method was lower than in the previous cases with water and salt. However, thanks to the $3.4 \mathrm{MHz}$ minimum peak, the concentration of water in oil could be calculated.

\section{Conclusions}

Fluid degradation is the cause of failure in many industrial processes or machines. For example, in the field of electrical machines, power transformers and large turbo-generators need pure oil and water, respectively. In power transformers, the oil, used as cooling and insulating medium, should not be contaminated with water. Otherwise, insulation failures can take place with severe consequences. In large generators, the cooling systems comprise pure water to directly cool down the stator windings. This water should have an extremely low conductivity; otherwise, an internal fault could take place.

In the paper, the design of a fluid core double coil sensor prototype was presented. The prototype was manufactured, and numerous experimental tests were performed to detect contamination of pure water with salt and contamination of transformer oil with water. In both cases, it was possible not only to detect contamination but also to estimate the amount of contaminant. For this, the minimum gain in the transfer function, corresponding to the resonant frequency was analyzed. Monotonic behaviors were observed in both cases. Hence, fit curves were calculated.

In addition, a simulation model was presented. The simulation model was based on the equivalent electric circuit of the double coil sensor. In this case, pure water contaminated with salt was used for the simulations. Numerous simulations were carried out, varying the components of the equivalent electric circuit of the model according to the salt quantity in the water. Similar results to the experimental tests were obtained.

In this paper, a novel sensor to detect fluid degradation or contamination was presented. The diagnosis technique was based on analyzing the frequency response analysis (FRA) of the sensor immersed in the tested fluid. The sensor comprised two coils with an open core. The first coil was fed at constant voltage with variable frequency (from $20 \mathrm{~Hz}$ to $20 \mathrm{MHz}$ ), while the voltage in the second coil was recorded. Afterward, its transfer function was calculated, dividing the voltage measured in the second coil with the voltage injected in the first one. The FRA test performed in normal operating conditions was considered as the reference test. The changes in the FRA tests were due to variations in the magnetic permeability, electric permittivity, and resistivity of the fluid. Therefore, if there is a contamination or degradation in the fluid, it can be detected by comparing an FRA test with the FRA reference test.

In terms of future research, the double-coil sensor dived in the power transformer tank must be tested with higher voltages, so as to create higher fluxes that would induce larger voltages in the second coil and improve the sensitivity of the method. Besides, temperature influence will be considered and corrected with experimental parameters to standard ranges. For this, numerous experimental FRA tests must be conducted for different temperatures and pollution sweeps. These improvements can be important for developing a sensor that allows online fluid degradation measurement.

\section{Patents}

As a result of this work, a patent has been applied for, Spanish Patent P202030539 "Sistema y método de medición de degradación o contaminación de fluidos mediante un sensor inductivo de núcleo hueco". 
Author Contributions: Conceptualization, C.A.P.; methodology, J.M.G.; validation, A.E.C.; formal analysis, J.M.G. and A.E.C.; investigation, J.M.G., A.E.C., J.Á.S.-F., and C.A.P.; resources, A.E.C. and C.A.P.; writing-original draft preparation, A.E.C. and J.M.G.; writing-review and editing J.M.G., J.Á.S.-F., and C.A.P.; supervision, J.Á.S.-F. and C.A.P.; project administration, J.Á.S.-F. All authors have read and agreed to the published version of the manuscript.

Funding: This research was funded by Universidad Politécnica de Madrid, grant number RP1604330010.

Acknowledgments: The authors gratefully acknowledge the contributions of Allani, Díaz, Talavera, Peña, and Martín for their implication in this work.

Conflicts of Interest: The authors declare no conflict of interest.

\section{Nomenclature}

A Gain

$\alpha \quad$ Mathematical coefficient (salt in water model)

$\beta \quad$ Mathematical coefficient (salt in water model)

C Pollutant agent concentration

$\mathrm{C}_{\text {fluid }} \quad$ Fluid capacitance between coils and ground

$\mathrm{C}_{\text {turns1 }} \quad$ Capacitance between turns in first coil

$\mathrm{C}_{\text {turns2 }}$ Capacitance between turns in second coil

$\gamma \quad$ Mathematical coefficient (water in oil model)

d Wire diameter

$\mathrm{D}_{\mathrm{Cu} 1 \mathrm{Cu} 2}$ Distance between equivalent conductors

$\delta \quad$ Mathematical coefficient (water in oil model)

$\varepsilon \quad$ Electric permittivity

$k_{1} \quad$ Mathematical coefficient (salt in water model)

$k_{2} \quad$ Mathematical coefficient (salt in water model)

$k_{1}{ }^{\prime} \quad$ Mathematical coefficient (water in oil model)

$k_{2}^{\prime} \quad$ Mathematical coefficient (water in oil model)

$l \quad$ Average length of the magnetic circuit

$\mathrm{L}_{1} \quad$ First coil inductance

$\mathrm{L}_{2} \quad$ Second coil inductance

$\mathrm{l}_{\mathrm{Cu}} \quad$ Conductor's length

$\mathrm{L}_{\mu} \quad$ Magnetizing inductance

N Turns number

$\mu \quad$ Magnetic permeability

$\mathrm{R}_{\mathrm{Cu} 1} \quad$ First coil wire resistance

$\mathrm{R}_{\mathrm{Cu} 2} \quad$ Second coil wire resistance

$\mathrm{R}_{\text {fluid }} \quad$ Fluid resistance between coils and ground

$\mathrm{R}_{\text {turns1 }} \quad$ Resistance between turns in first coil

$R_{\text {turns2 }}$ Resistance between turns in second coil

$\rho \quad$ Electric resistivity

$S \quad$ Magnetic gap section

$\mathrm{S}_{\mathrm{Cu}} \quad$ Conductor's section

$\mathrm{U}_{\text {in }} \quad$ Input voltage

$\mathrm{U}_{\text {out }}$ Output voltage

$\mathrm{Z} \quad$ Impedance

\section{References}

1. Yanaseko, T.; Sato, H.; Kuboki, I.; Mossi, K.; Asanuma, H. Vibration Viscosity Sensor for Engine Oil Monitoring Using Metal Matrix Piezoelectric Composite. Materials 2019, 12, 3415. [CrossRef] [PubMed]

2. Beckers, K.F.; Glatzmaier, G.C. Addressing solar power plant heat transfer fluid degradation: Experimental measurements of hydrogen transport properties in binary eutectic biphenyl/diphenyl ether. Sol. Energy 2018, 173, 304-312. [CrossRef] 
3. Martinez, A.; Astrain, D.; Rodriguez, A. Zero-power-consumption thermoelectric system to prevent overheating in solar collectors. Appl. Therm. Eng. 2014, 73, 1103-1112. [CrossRef]

4. Rao, U.M.; Sood, Y.R.; Jarial, R.K. Oxidation stability enhancement of a blend of mineral and synthetic ester oils. IEEE Electr. Insul. Mag. 2016, 32, 43-47. [CrossRef]

5. Xu, Y.; Qian, S.; Liu, Q.; Wang, Z.D. Oxidation stability assessment of a vegetable transformer oil under thermal aging. IEEE Trans. Dielectr. Electr. Insul. 2014, 21, 683-692. [CrossRef]

6. Guo, P.; He, W.; García-Naranjo, J.C. Degradation of Phosphate Ester Hydraulic Fluid in Power Station Turbines Investigated by a Three-Magnet Unilateral Magnet Array. Sensors 2014, 14, 6797-6805. [CrossRef]

7. Turanova, O.A.; Bikkinyaeva, Y.K.; Gafiyatullin, L.G.; Gnezdilov, O.; Kozlov, V.K.; Turanov, A.N. Role of Aromatic Hydrocarbons in Sediment Formation in Transformer Oil. Chem. Technol. Fuels Oils 2014, 49, 517-521. [CrossRef]

8. Yu, H.; Yu, P.; Luo, Y. Renewable Low-viscosity Dielectrics Based on Vegetable Oil Methyl Esters. J. Electr. Eng. Technol. 2017, 12, 820-829. [CrossRef]

9. Jalbert, J.; Rodriguez-Celis, E.; Duchesne, S.; Morin, B.; Ryadi, M.; Gilbert, R. Kinetics of the production of chain-end groups and methanol from the depolymerization of cellulose during the ageing of paper/oil systems. Part 3: Extension of the study under temperature conditions over $120^{\circ} \mathrm{C}$. Cellulose 2015, 22, 829-848. [CrossRef]

10. Raposo, H.D.N.; Farinha, J.T.; Fonseca, I.; Ferreira, L. Condition Monitoring with Prediction Based on Diesel Engine Oil Analysis: A Case Study for Urban Buses. Actuators 2019, 8, 14. [CrossRef]

11. Aslam, M.; Arbab, M.N.; Basit, A.; Ahmad, T.; Aamir, M. A review on fault detection and condition monitoring of power transformer. Int. J. Adv. Appl. Sci. 2019, 6, 100-110.

12. Islam, M.; Lee, G.; Hettiwatte, S.N. A review of condition monitoring techniques and diagnostic tests for lifetime estimation of power transformers. Electr. Eng. 2017, 100, 581-605. [CrossRef]

13. Kozlov, V.; Turanov, A.N. Transformer oil and modern physics. IEEE Trans. Dielectr. Electr. Insul. 2012, 19, 1485-1497. [CrossRef]

14. Sun, C.; Ohodnicki, P.R.; Stewart, E.M. Chemical Sensing Strategies for Real-Time Monitoring of Transformer Oil: A Review. IEEE Sens. J. 2017, 17, 5786-5806. [CrossRef]

15. N'Cho, J.S.; Fofana, I.; Hadjadj, Y.; Beroual, A. Review of Physicochemical-Based Diagnostic Techniques for Assessing Insulation Condition in Aged Transformers. Energies 2016, 9, 367. [CrossRef]

16. Arakelian, V. Effective diagnostics for oil-filled equipment. IEEE Electr. Insul. Mag. 2002, 18, 26-38. [CrossRef]

17. Saha, T.K. Review of modern diagnostic techniques for assessing insulation condition in aged transformers. IEEE Trans. Dielectr. Electr. Insul. 2003, 10, 903-917. [CrossRef]

18. Cheim, L.; Duval, M.; Haider, S. Combined Duval Pentagons: A Simplified Approach. Energies 2020, 13, 2859. [CrossRef]

19. Hadjadj, Y.; Fofana, I.; Sabau, J.; Briosso, E. Assessing insulating oil degradation by means of turbidity and UV/VIS spectrophotometry measurements. IEEE Trans. Dielectr. Electr. Insul. 2015, 22, 2653-2660. [CrossRef]

20. Fofana, I.; Hadjadj, Y. Electrical-Based Diagnostic Techniques for Assessing Insulation Condition in Aged Transformers. Energies 2016, 9, 679. [CrossRef]

21. Zaengl, W. Applications of dielectric spectroscopy in time and frequency domain for HV power equipment. IEEE Electr. Insul. Mag. 2003, 19, 9-22. [CrossRef]

22. Csepes, G.; Hámos, I.; Brooks, R.; Karius, V. Practical foundations of the RVM (recovery voltage method for oil/paper insulation diagnosis). In Proceedings of the 1998 Annual Report Conference on Electrical Insulation and Dielectric Phenomena (Cat. No.98CH36257), Atlanta, GA, USA, 25-28 October 1998; Volume 1, pp. 345-355. [CrossRef]

23. Blennow, J.; Ekanayake, C.; Walczak, K.; Garcia, B.; Gubanski, S. Field Experiences With Measurements of Dielectric Response in Frequency Domain for Power Transformer Diagnostics. IEEE Trans. Power Deliv. 2006, 21, 681-688. [CrossRef]

24. Yang, L.; Gubanski, S.M.; Serdyuk, Y.V.; Schiessling, J. Dielectric properties of transformer oils for HVDC applications. IEEE Trans. Dielectr. Electr. Insul. 2012, 19, 1926-1933. [CrossRef]

25. Aljohani, O.; Abu-Siada, A. Application of digital image processing to detect transformer bushing faults and oil degradation using FRA polar plot signature. IEEE Trans. Dielectr. Electr. Insul. 2017, 24, 428-436. [CrossRef] 
26. Torres-Perez, A.; Hadfield, M. Low-Cost Oil Quality Sensor Based on Changes in Complex Permittivity. Sensors 2011, 11, 10675-10690. [CrossRef] [PubMed]

27. Golnabi, H. Measurements of the electrical parameters for different water samples. Measurement 2011, 44, 2175-2184. [CrossRef]

28. Chaouche, M.S.; Houassine, H.; Moulahoum, S.; Colak, I. BA to construction of equivalent circuit of a transformer winding from frequency response analysis measurement. IET Electr. Power Appl. 2018, 12, 728-736. [CrossRef]

29. Zhao, X.; Yao, C.; Abu-Siada, A.; Liao, R. High frequency electric circuit modeling for transformer frequency response analysis studies. Int. J. Electr. Power Energy Syst. 2019, 111, 351-368. [CrossRef]

30. Chanane, A.; Houassine, H.; Bouchhida, O. Enhanced modelling of the transformer winding high frequency parameters identification from measured frequency response analysis. IET Gener. Transm. Distrib. 2019, 13, 1339-1345. [CrossRef]

31. Beril, I.I.; Bologa, M.K. Temperature dependence of the electric conductivity of low conducting organic liquids. Surf. Eng. Appl. Electrochem. 2010, 46, 235-236. [CrossRef]

(C) 2020 by the authors. Licensee MDPI, Basel, Switzerland. This article is an open access article distributed under the terms and conditions of the Creative Commons Attribution (CC BY) license (http://creativecommons.org/licenses/by/4.0/). 